\title{
STEROIDAL SAPONINS FROM SOLANUM UNGUICULATUM (A.) RICH
}

\author{
Fawkeya A. Abbas \\ Department of Pharmacognosy, Faculty of Pharmacy \\ Zagazig University, Zagazig, Egypt
}

Key word Index: Solanum unguiculatum, Solanaceae; steroidal saponins; diosgenin; chlorogenin; diosgenin glycoside; laxogenin glycoside; isonarthogenin glycoside, spirostanol glycoside

\begin{abstract}
Seven steroidal saponins were isolated for the first time from the green berries of Solanum unguiculatum. Their structures were determined by spectroscopic analysis as well as hydrolysis of the glycosides into the corresponding sapogenins, diosgenin, chlorogenin, diosgenin-3-O- $\beta-D-$ galactopyranoside, diosgenin-3-O- $\beta$-D-glucopyranosyl-(1 $\rightarrow 4)-\beta$-Dgalactopyranoside, $3 \beta$-hydroxyl-(25R) $5 \alpha$-spirostan-6-one (laxogenin) 3-O- $\alpha-\mathrm{L}$ rhamnopyranosyl-(1 $\rightarrow$ 2)- $\beta$-D-glucopyranoside, isonarthogenin-3-O- $\alpha-\mathrm{L}$ rhamnopyranosyl-(1 $\rightarrow$ 2)-O-[ $\alpha$-L-rhamnopyranosyl-(1 $\rightarrow 4)$ - $\beta$-D-glucopyranoside and 25 (S) spirost-5-en-3 $\beta, 17 \alpha, 27$ triol-3-O-[ $\alpha$-L-rhamnopyranosyl$(1 \rightarrow 2)$ ] [ $\alpha$-L-rhamnopyranosyl $(1 \rightarrow 4)]$ - $\beta$-D-glucopyranoside.
\end{abstract}

\section{INTRODUCTION}

The occurrence of steroidal saponins in Solanum plants is well documented $^{(1-16)}$. In our previous paper ${ }^{(17)}$ we reported on the isolation and structure determination of new steroidal alkaloids from Solamum unguiculatum (A.) Rich. A survey of literature showed that no chemical work has been reported on the saponins from Solanum unguiculatum (A.) Rich. This small tree is widely distributed in Yemen, Sana'a region and its fruits are known for their 
foaming properties, indicating the presence of saponins. As part of our contribution to the study of $S$. unguiculatum (A.) Rich we have now carried out a phytochemical study of the chloroform and n-butanol-soluble parts of the methanolic extract of $S$. unguiculatum (A.) Rich. This resulted in the isolation of seven saponins.

\section{EXPERIMENTAL}

\section{GENERAL}

MPs; were measured on a Fisher-Johns hot stage and are uncorr. Optical rotations were measured on a Zeiss polarimeter Model 53187 using a sodium lamp. NMR spectra were measured in $\mathrm{CDCl}_{3}$ and pyridine- $\mathrm{d}_{5}$ and recorded at $300 \mathrm{MHz}$ for ${ }^{1} \mathrm{HNMR}$ and $75 \mathrm{MHz}$ for ${ }^{13} \mathrm{CNMR}$ (using TMS as internal standard) on a Varian XL300 (Darmstadt, Germany). Chemical shifts are expressed in $\delta$ values $\left({ }^{1} \mathbf{H}\right)$ and ppm $\left({ }^{13} \mathrm{C}-\mathrm{nmr}\right)$. IR spectra were recorded on a Perkin-Elmer Model 377 spectrometer in $\mathrm{KBr}$ discs. FAB-MS spectra were recorded with an MS 2500 high resolution spectrometer (Kratos Manchester, UK) with $70 \mathrm{eV}$, an ion source temperature of $180^{\circ} \mathrm{C}$ and a direct inlet using sulphur glycerol as matrix. Petroleum-ether used with bp 60-80'; chromatography silica gel (60-120 mesh); TLC: precoated Kieselgel $60 \mathrm{~F}_{254}(0.25 \mathrm{~mm}$ thick, Merck). The spots were visualized by spraying with $10 \% \mathrm{H}_{2} \mathrm{SO}_{4}$ solution followed by heating at $100^{\circ} \mathrm{C}$ for 10 minutes. Solvent system for TLC: $\mathrm{CHCl}_{3}-\mathrm{MeOH}-\mathrm{EtOH}-\mathrm{H}_{2} \mathrm{O}(60: 20: 15: 6)$.

\section{PLANT MATERIAL:}

Green berries (1 $\mathrm{kg}$ ) of $S$. unguiculatum were collected in August, 1991 from road and hill sides in Sana'a region (Wadi Zahr) in Yemen. The identity of the plant was confirmed by Professor M. El-Manayery, Faculty of Science, ElAzhar University, Egypt. A certified specimen has been deposited at the Pharmacognosy Department, Faculty of Pharmacy, Zagazig University, Egypt. 


\section{EXTRACTION AND CHROMATOGRAPHY}

The fresh fruits were cut into pieces and exhaustively extracted with methanol $(4 \mathrm{~L})$ by cold maceration. The extract was concentrated to almost dryness under reduced pressure. The residue $(20 \mathrm{~g})$ was suspended in water $(1 / 2 \mathrm{~L})$ and extracted with $\mathrm{CHCl}_{3}(2 \mathrm{~L})$ and then with $\mathrm{n}-\mathrm{BuOH}(2 \mathrm{~L})$. The chloroform-soluble phase was concentrated under reduced pressure, the resulting residue $(7 \mathrm{~g}$.) was chromatographed over silica gel column. Elution being carried out with petroleum-ether, increasing the polarity with EtOAc, early petrol-EtOAc (9:1) eluate fractions yielded compound $1(50 \mathrm{mg})$ and petrol-EtOAc (3:7) eluate fractions yielded compound $2(100 \mathrm{mg})$.

The n-BuOH-soluble phase was concentrated under reduced pressure and the resulting residue $(10 \mathrm{~g})$ was chromatographed over silica gel column. Elution being carried out with chloroform then increasing the polarity with methanol. Chloroform-methanol (93:7) eluate fractions yielded compound 3 (30 mg), chloroform-methanol (90:10) eluate fractions yielded compound 4 (140 mg), chloroform-methanol (80:20) eluate fractions yielded compound 5 (100 mg); chloroform-methanol (70:30) eluate fractions yielded a mixture of 2 spots (compounds 6 and 7) (300 mg). The latter mixture were rechromatographed on silica gel column and elution was started with chloroform-methanol (80:20) increasing the polarity with methanol, fractions (60-40) yielded compound $6(120$ $\mathrm{mg}$ ) and fractions (45-55) yielded compound 7 (120 $\mathrm{mg}$ ).

Compound (1) eluted with petrol-EtOAc (9:1) on further preparative chromatography furnished diosgenin $\left(50 \mathrm{mg}\right.$ ) crystallizing from $\mathrm{CHCl}_{3}$-petrol in colourless needles $\mathrm{mp} 205^{\circ} \mathrm{C}$ [lit. $\left.206^{\circ} \mathrm{C}\right],[\alpha]_{\mathrm{D}}^{20}-126^{\circ} \mathrm{C}\left(\mathrm{CHCl}_{3} ; 0.096\right)$ [lit $\left.[\alpha]_{\mathrm{D}}^{20}-121^{\circ}\right] ;{ }^{\mathrm{l}} \mathrm{HNMR}\left(300 \mathrm{MHz}, \mathrm{CDCl}_{3}\right): \delta .78\left(3 \mathrm{H}, \mathrm{d}, \mathrm{J}=6.2 \mathrm{~Hz}, \mathrm{CH}_{3}-27\right), 1.01$ (3H, d, J=6.1 Hz, $\left.\mathrm{CH}_{3}-21\right), 1.03\left(6 \mathrm{H}, \mathrm{s}, \mathrm{CH}_{3}-18\right.$ and $\left.\mathrm{CH}_{3}-19\right), 2.28\left(3 \mathrm{H}, \mathrm{m}, \mathrm{H}_{2}-4\right.$ and $\left.\mathrm{H}_{\mathrm{equ}}-7\right), 3.32$ - $3.51\left(3 \mathrm{H}, \mathrm{m}, \mathrm{H}-3\right.$ and $\left.\mathrm{CH}_{2}-26\right), 4.36-4.43(1 \mathrm{H}, \mathrm{m}, \mathrm{CH}-16)$, $5.34(1 \mathrm{H}, \mathrm{d}, \mathrm{J}=5.1 \mathrm{~Hz}, \mathrm{CH}-6) .{ }^{13} \mathrm{CNMR}$ see Table 1 . 
Compound (2) eluted with petrol-EtOAc (3:7) on further preparative chromatography furnished chlorogenin $(100 \mathrm{mg}$ ) crystallized from $\mathrm{MeOH}$ as fine needles mp $268-270^{\circ} \mathrm{C},[\alpha]_{\mathrm{D}}^{20}-42^{\circ}(\mathrm{MeOH} ; 0.4)$, HRFABMS (neg.) mlz 430 [M$\mathrm{H}^{-}$, calculated for $\mathrm{C}_{27} \mathrm{H}_{43} \mathrm{O}_{4}, 394,358,316,298,269,139$ (base peak-1 $\left.\mathrm{C}_{9} \mathrm{H}_{15} \mathrm{O}_{1}\right)$. IR $U_{\max }^{\mathrm{KBr}} \mathrm{cm}^{-1} 3400,985,922,900 \mathrm{~cm}^{-1} .{ }^{1} \mathrm{HNMR}\left(300 \mathrm{MHz}, \mathrm{CDCl}_{3}\right) \delta$ 0.77 (3 H, s, Me-18), $0.84(3 \mathrm{H}, \mathrm{s}, \mathrm{Me}-19), 0.94(3 \mathrm{H}, \mathrm{d}, \mathrm{J}=7 \mathrm{~Hz}, \mathrm{Me}-21), 0.78$ $(3 \mathrm{H}, \mathrm{d}, \mathrm{J}=7 \mathrm{~Hz}, \mathrm{Me}-27), 2.15\left(1 \mathrm{H}, \mathrm{s}, \mathrm{C}_{3}-\beta-\mathrm{OH}\right), 3.35(1 \mathrm{H}, \mathrm{m}, \mathrm{C}-16-\alpha-\mathrm{H}), 3.4$ $(1 \mathrm{H}, \mathrm{s}, \mathrm{C}-6-\alpha-\mathrm{OH}), 4.35$ (1H, m, C-6 HOH). ${ }^{13} \mathrm{CNMR}$ see table 1.

Compound (3) eluted with $\mathrm{CHCl}_{3}-\mathrm{MeOH}$ (93:7) on further column chromatography furnished diosgenin glycoside $(130 \mathrm{mg})$ as powder from $\mathrm{MeOH}$, FABMS (neg.) $575\left[\mathrm{M}\left(\mathrm{C}_{33} \mathrm{H}_{52} \mathrm{O}_{8}\right)-\mathrm{H}\right]^{-} ;{ }^{1} \mathrm{HNMR}: 0.7(3 \mathrm{H}, \mathrm{d}, \mathrm{J}=6.5 \mathrm{~Hz}, \mathrm{Me}-27)$, 0.9 (3H, s, Me-19), 1.0 (3 H, s, Me-18), 1.37 (3H, d J= 7Hz, Me-21) 4.98 (1H, d, $\mathrm{J}=8 \mathrm{~Hz}, \mathrm{Gal} . \mathrm{H}-1), 5.29$ (br, s, H-6). ${ }^{13} \mathrm{CNMR}$ see (Table 1).

Compound (4) eluted with $\mathrm{CHCl}_{3}-\mathrm{MeOH}(90: 10)$ on further column chromatography furnished laxogenin glycoside (140 mg) needles from $\mathrm{MeOH}$, mp $247-249^{\circ}($ dec. $),[\alpha]_{D}^{20}-60.4^{\circ}(\mathrm{MeOH} ; \mathrm{C} 0.51)$, -neg. FABMS m/z $737[\mathrm{M}$ $\left.\left(\mathrm{C}_{39} \mathrm{H}_{62} \mathrm{O}_{13}\right)-\mathrm{H}\right]^{-}, 575$ [M-Glc.-H] ${ }^{-} ;{ }^{1} \mathrm{HNMR}: \delta 0.7(3 \mathrm{H}, \mathrm{d}, \mathrm{J}=6 \mathrm{~Hz}, \mathrm{Me}-27), 0.93$ $(3 \mathrm{H}, \mathrm{s}, \mathrm{Me}-19), 0.82(3 \mathrm{H}, \mathrm{s}, \mathrm{Me}-18), 0.84(3 \mathrm{H}, \mathrm{d}, \mathrm{J}=7 \mathrm{~Hz}, \mathrm{Me}-21), 4.35(1 \mathrm{H}, \mathrm{d}$, $\mathrm{J}=8 \mathrm{~Hz}, \mathrm{Gal} . \mathrm{H}-1), 5.29(1 \mathrm{H}, \mathrm{br}, \mathrm{s}, \mathrm{H}-6), 5.33(1 \mathrm{H}, \mathrm{d}, \mathrm{J}=7.7 \mathrm{~Hz}, \mathrm{Glc} \mathrm{H}-1)$.

Compound (5) eluted with $\mathrm{CHCl}_{3}-\mathrm{MeOH}$ (80:20) on further chromatography furnished compound-5 as amorphous powder $[\alpha]_{D}^{25}-90(\mathrm{MeOH}$, C 0. 04), positive FABMS m/z $777[\mathrm{M}+\mathrm{K}]^{+}, 762[\mathrm{M}+\mathrm{Na}+\mathrm{H}]^{+}, 721[\mathrm{M}-\mathrm{OH}]^{+}$, UV $\lambda_{\max } \mathrm{MeOH} 284 ; \quad I R V_{\max }^{\mathrm{KBr}} \mathrm{cm}^{-1} ; 3440(\mathrm{OH}), 2940,2870(\mathrm{CH}), 1705(\mathrm{C}=0)$, $1455,1375,1260,1175,1045,975,915,895,800,700$ [(25R)-spiroacetal intensity $915<895$ ]. ${ }^{1} \mathrm{HNMR}(300 \mathrm{MHz}$, pyridine-ds): $\delta 4.53(1 \mathrm{H}$, qu-like, $\mathrm{J}=7$ $\mathrm{Hz}, \mathrm{H}-16), 3.96$ (1H, m, H-3), 3.59 (1H, dd, J=10.6, $3.6 \mathrm{~Hz}, \mathrm{H}-26 \mathrm{a}), 3.49$ (1H, dd, J=10.6 Hz, H-26b), $2.37(1 \mathrm{H}, \mathrm{dd}, \mathrm{J}=12.7,4.1 \mathrm{~Hz}, \mathrm{H}-7 \mathrm{equ}), 2.16$ (1H dd, $J=12.6,2.4 \mathrm{~Hz}, \mathrm{H}-5), 2(1 \mathrm{H}, \mathrm{dd}, \mathrm{J}=12.7,12.7 \mathrm{~Hz}, \mathrm{H}-7 \mathrm{ax}), 1.15(3 \mathrm{H}, \mathrm{d}, \mathrm{J}=6.9 \mathrm{~Hz}$, 
Me-21), 0.79 (3H, s, Me-18), $0.7(3 \mathrm{H}, \mathrm{d}, \mathrm{J}=5.8 \mathrm{~Hz}, \mathrm{Me}-27), 0.64$ (3H, s, Me-19), $4.93\left(1 \mathrm{H}, \mathrm{d}, \mathrm{J}=7.8 \mathrm{~Hz}, \mathrm{H}-1^{\prime}\right), 3.88\left(1 \mathrm{H}, \mathrm{dd}, \mathrm{J}=9.3,7.8 \mathrm{~Hz}, \mathrm{H}-2^{\prime}\right), 4.22$ (overlapping H-3'), $4.45\left(1 \mathrm{H}\right.$, dd, J=9.3, $\left.9.3 \mathrm{~Hz} \mathrm{H}-4^{\prime}\right), 3.96\left(1 \mathrm{H}, \mathrm{m}, \mathrm{H}-5^{\prime}\right), 4.83$ $\left(1 \mathrm{H}, \mathrm{br}, \mathrm{d}, \mathrm{J}=10.4, \mathrm{H}-6^{\prime} \mathrm{a}\right), 4.68\left(1 \mathrm{H}, \mathrm{dd}, \mathrm{J}=10.8,3.6 \mathrm{~Hz}, \mathrm{H}-6^{\prime} \mathrm{b}\right), 6.33$ (1H, br s, H-1")m $4.76\left(1 \mathrm{H}\right.$, br d, J=3.4 Hz, H-2"), $4.64\left(1 \mathrm{H}, \mathrm{dd}, \mathrm{J}=9.5,3.4 \mathrm{~Hz}, \mathrm{H}-3^{\prime \prime}\right)$, $4.42\left(1 \mathrm{H}, \mathrm{dd}, \mathrm{J}=9.5,9.5 \mathrm{~Hz}, \mathrm{H}-4^{\prime \prime}\right), 4.96\left(1 \mathrm{H}, \mathrm{d}\right.$ qu, J=9.5, $\left.6.2 \mathrm{~Hz}, \mathrm{H}-5^{\prime \prime}\right)$.

Compound (6) eluted with $\mathrm{CHCl}_{3}-\mathrm{MeOH}$ (70:30) on further chromatography furnished compound 6 as amorphous powder, $[\alpha]_{D}^{30}$ $76^{\circ}(\mathrm{MeOH} ; \mathrm{C} \quad 0.08)$, positive FABMS mlz $885[\mathrm{M}+\mathrm{H}]^{+}$; IR $\mathrm{U}_{\max }^{\mathrm{KBr}} \mathrm{cm}^{-1}$ $3400(\mathrm{OH}), 2923$ and $2857(\mathrm{CH}), 1458,1250,1094,1055,985,840 .{ }^{1} \mathrm{HNMR}$ (pyridine- $\mathrm{d}_{5}$ ): $\left.\delta 6.381 \mathrm{H}, \mathrm{br}, \mathrm{s}, \mathrm{H}-1^{\prime \prime}\right), 5.84\left(1 \mathrm{H}, \mathrm{br}, \mathrm{s}, \mathrm{H}-1^{\prime \prime \prime}\right), 5.33(1 \mathrm{H}, \mathrm{br}, \mathrm{d}$, $\mathrm{J}=4.4 \mathrm{~Hz}, \mathrm{H}-6), 4.94\left(1 \mathrm{H}, \mathrm{d}, \mathrm{J}=7 \mathrm{~Hz}, \mathrm{H}-\mathrm{l}^{\prime}\right) 1.77\left(3 \mathrm{H}, \mathrm{d}, \mathrm{J}=6 \mathrm{~Hz}, \mathrm{H}-6^{\prime \prime}\right) 1.6(3 \mathrm{H}, \mathrm{d}$, $\left.\mathrm{J}=6 \mathrm{~Hz}, \mathrm{H}-6^{\prime \prime \prime}\right) 1.16(3 \mathrm{H}, \mathrm{d}, \mathrm{J}=7 \mathrm{~Hz}, \mathrm{Me}-21), 1.06(3 \mathrm{H}, \mathrm{s}, \mathrm{Me}-19), 0.85(3 \mathrm{H}, \mathrm{s}, \mathrm{Me}-$ 18).

Compound (7) eluted with, $\mathrm{CHCl}_{3}-\mathrm{MeOH}$ (70:30) on further column chromatography furnished compound 7 as amorphous powder with mp $300^{\circ} \mathrm{C}\left(\right.$ dec.), $[\alpha]_{D}^{30}-90^{\circ}$ (pyridine; C 0.98 ), IR $V_{\max }^{\mathrm{KBr}} \quad \mathrm{cm}^{-1} 3400(\mathrm{OH}), 1637$ $(\mathrm{C}=\mathrm{CH}), \quad 1040$ (C-O-C), 993 (25-S-27-hydroxyl spriostanol), 838, $812\left(\Delta^{5}\right)$. FABMS m/z $923(\mathrm{M}+\mathrm{Na})^{+}, 907(\mathrm{M}+\mathrm{Li})^{+},{ }^{1} \mathrm{HNMR}: \delta 0.96(3 \mathrm{H}, \mathrm{s}, \mathrm{Me}-18), 1.08$ $(3 \mathrm{H}, \mathrm{s}, \mathrm{Me}-19) ; 1.22(3 \mathrm{H}, \mathrm{d}, \mathrm{J}=7 \mathrm{~Hz}, \mathrm{Me}-21), 2.25(1 \mathrm{H}, \mathrm{qu}, \mathrm{J}=7 \mathrm{~Hz}, \mathrm{H}-20)$, 2.71(1H, m, H-25), 3.6(1H, dd, J=11.9, 7Hz, H-27a), $3.7(1 \mathrm{H}, \mathrm{dd}, \mathrm{J}=12,1 \mathrm{~Hz}, \mathrm{H}-$ 27b), 3.8 (1H, dd, J=14, 12Hz, $\left.\mathrm{H}_{26 \alpha \beta}, 26_{\alpha} / 25\right), 2.68$ (1H, dd, J = 14, $4 \mathrm{~Hz}, \mathrm{H}_{26 \alpha \beta}$, $\left.\mathrm{H}-26_{\beta} / 25\right), 5.3(1 \mathrm{H}, \mathrm{m}, \mathrm{H}-5), 4.9(1 \mathrm{H}, \mathrm{d}, \mathrm{J}=6 \mathrm{~Hz}$, Glc. H-1), $5.82(1 \mathrm{H}, \mathrm{br}, \mathrm{s}, 4-\mathrm{Rha}$. $\mathrm{H}-1), 6.36$ (1H, br s, 2-Rha. H-1). ${ }^{13} \mathrm{CNMR}$ (Table 1)

\section{ACID HYDROLYSIS OF THE GLYCOSIDES}

Acid hydrolysis of compounds 3 - 7: A solution of each saponin (about 5 $\mathrm{mg})$ in $2 \mathrm{NHCl}$-dioxane- $\mathrm{H}_{2} \mathrm{O}(1: 1 \mathrm{ml})$ was heated separately for $6 \mathrm{hr}$. The reaction 
mixture was blown to dryness with a $\mathrm{N}_{2}$ stream, the residue was checked respectively. For identification of aglycone and sugar moieties. Aglycones were identified using TLC and comparison with authentic samples using $\left(\mathrm{CHCl}_{3}\right.$ $\mathrm{MeOH}, 12: 1)$ as developer and $10 \% \mathrm{H}_{2} \mathrm{SO}_{4}$ for detection. Saponins 3 and 4 gave diosgenin ( $R_{f}$ 0.77), saponin 5 gave laxogenin $\left(R_{f} 0.56\right)$, saponin 6 gave isonarthogenin ( $\left.R_{f} \quad 0.5\right)$ and compound 7 gave isonarthagenin. -17-OH $\left(R_{f} 0.53\right)$. Sugars were checked with TLC carried out on silica gel $F_{254}$ plate using n-BuOHPrOH- $\mathrm{H}_{2} \mathrm{O}(10: 5: 4)$ as developer and anisaldehyde $-\mathrm{H}_{2} \mathrm{SO}_{4}$ for detection. Saponin 3 gave Gal. $\left(R_{f} 0.24\right)$, saponin 4 gave Gal. $\left(R_{f} 0.24\right)$ and GLc. $\left(R_{f} 0.29\right)$, while saponin 5-7 gave Glc. $\left(R_{f} 0.29\right)$ and $R h a .\left(R_{f} 0.57\right)$.

\section{RESULTS AND DISCUSSION}

The residue remaining from methanolic extract of the green berries of $S$. unguiculatum was partitioned between chloroform and $\mathrm{H}_{2} \mathrm{O}$ then between $\mathrm{n}$ butanol and $\mathrm{H}_{2} \mathrm{O}$. A series of chromatographic separations of the chloroformsoluble phase and n-butanol-soluble phase furnished compounds 1,2 and 3-7 respectively.

Compound 1 crystallized from chloroform-petrol mixture as colourless needles with mp. $205^{\circ} \mathrm{C},[\alpha]_{\mathrm{D}}-126^{\circ}\left(\mathrm{CHCl}_{3}\right)$. The ${ }^{1} \mathrm{HNMR}\left(300 \mathrm{MHz}, \mathrm{CDCl}_{3}\right)$ spectrum suggested the presence of two secondary methyl groups at $\delta 0.78(\mathrm{~d}$, $\mathrm{J}=6.2 \mathrm{~Hz})$ and $1.01(\mathrm{~d}, \mathrm{~J}=6.1 \mathrm{~Hz})$, two tertiary methyl groups as singlet at $\delta 1.03$ and an olefinic proton appearing at 5.34 as doublet $(\mathrm{J}=5.1 \mathrm{~Hz})^{(18)}$. A comparison of the carbon shifts for 1 with those of diosgenin ${ }^{(19-20)}$ led to the assignment of all the carbon shifts and elucidation of the structure and stereochemistry of 1 as diosgenin (Table 1). The ${ }^{13} \mathrm{CNMR}$ spectrum $\left(75 \mathrm{MHz}, \mathrm{CDCl}_{3}\right.$ ) of 1 showed the presence of signals appearing at $\delta 140.7,121.3$ are attributed to C-5 and C-6 respectively ${ }^{(21)}$, the observed close similarity of the shifts for C-23, C-24, C-25, $\mathrm{C}-26$ and $\mathrm{C}-27$ in compound 1 with those in diosgenin are diagnostic of the equatorial orientation of the C-25 methyl in the $22 \alpha$-O-spirostane skeleton and 
thus settled the $22 \mathrm{R}$ and $25 \mathrm{R}$ configuration of compound 1 . Diosgenin is thus shown to be (25R)-22 $\alpha$-O-spirost-5-ene-3 $\beta$-ol (1).

Compound 2 showed molecular ion peak at $\mathrm{m} / \mathrm{z} 430 \quad[\mathrm{M}-\mathrm{H}]^{-}$ corresponding to the molecular formula $\mathrm{C}_{27} \mathrm{H}_{43} \mathrm{O}_{4}$ with prominent peaks at $\mathrm{m} / \mathrm{z}$ 139 and 115 indicative of spiroketal moiety ${ }^{(22)}$. The IR spectrum showed prominent hydroxyl band, as well as the characteristic bands in the finger print zone attributed to the spiroketal moiety. Analysis of the IR spectrum indicated that 2 was a $25 \mathrm{R}$ spirostan because the $900 \mathrm{~cm}^{-1}$ band was more intense than 922 $\mathrm{cm}^{-1}$ band ${ }^{(23-24)}$. The ${ }^{13} \mathrm{C}-\mathrm{nmr}$ spectrum confirmed this conclusion. The F-ring carbons of compound 2 exhibited resonances at 109.2 ppm (C-22), 31.5 (C-23), 28.8 (C-24), 30.2 (C-25), 66.8 (C-26) and 16.2 (C-27). The carbons carrying hydroxyls appeared at 71.7 and $69.2 \mathrm{ppm}$. Thus, compound 2 was identified as chlorogenin by comparison of its $\mathrm{mp}$. and physical properties with the experimental values reported by Wall et al. ${ }^{(25)}$

Compound 3 showed a molecular ion peak at $\mathrm{m} / \mathrm{z} 575\left[\mathrm{M}\left(\mathrm{C}_{33} \mathrm{H}_{52} \mathrm{O}_{8}\right)-\mathrm{H}\right]^{-}$ in the negative FABmass spectrum. Upon acid hydrolysis, 3 yielded 1 as aglycone and galactose. In the ${ }^{1}$ HNMR spectrum of 3 , one anomeric proton signal was observed at $\delta 4.98(1 \mathrm{H}, \mathrm{d}, \mathrm{J}=8 \mathrm{~Hz})$ diagnostic for the $\beta$-configuration of the sugar moiety. It was observed that the glycosylation at the hydroxyl group of C-3 of the aglycone resulted in a downfield shift (6.3 ppm) of (C-3) Therefore, the structure of 3 was elucidated to be diosgenin-3-O- $\beta-D$ galactopyranoside.

Compound 4, demonstrated a molecular formula of $\mathrm{C}_{39} \mathrm{H}_{62} \mathrm{O}_{13}$ determined from the negative FABMS. Upon acid hydrolysis 4 yielded 1 as aglycone with galactose and glucose in ratio $1: 1$ as sugar components. In the ${ }^{1} \mathrm{HNMR}$ spectrum of 4 two anomeric proton signals were observed at $\delta 4.35(1 \mathrm{H}, \mathrm{d}, \mathrm{J}=8 \mathrm{~Hz})$ and $5.33(1 \mathrm{H}, \mathrm{d}, \mathrm{J}=7.7 \mathrm{~Hz})$, diagnostic of the $\beta$-configuration of the two sugars. Comparison of ${ }^{13} \mathrm{CNMR}$ spectrum of 4 with that of 3 indicated that the terminal glucose was attached at $\mathrm{C}-4$ of the inner galactose. The ${ }^{13} \mathrm{CNMR}$ spectrum of 4 indicted that it was a 3-O-diglycoside of 1 , for the signal of C-3 was shifted 
downfield at 77.7 where as the signals at C-2 and C-4 were displaced upfield at 30 and 39.1 respectively. Furthermore, a typical signal at 80 arising from the glycosylation at the hydroxyl of C -4 ' of galactose was confirmed. Based on the above evidence, the structure of 4 was proved to be diosgenin-3-O- $\beta-D-$ glucopyranosyl-(1 $\rightarrow$ 4)- $\beta$-D-galactopyranoside, identical to Funkioside C isolated from Funkia ovata ${ }^{(27)}$.

Compound 5 was assigned the molecular ion peaks at $\mathrm{m} / \mathrm{z} 777[\mathrm{M}+\mathrm{K}]^{+}$, $762[\mathrm{M}+\mathrm{Na}+\mathrm{H}]^{+}$and $721[\mathrm{M}-\mathrm{H}]^{-}$corresponding to the molecular formula $\mathrm{C}_{39} \mathrm{H}_{62} \mathrm{O}_{13}$. The IR spectrum indicated the existence of a hydroxyl group [3440 $\left.\mathrm{cm}^{-1}\right]$, a carbonyl group $\left[1705 \mathrm{~cm}^{-1}\right]$ and a (25R)-spiroacetal moiety (975, 915,895 and $\left.860 \mathrm{~cm}^{-1}\right)$, intensity $915<895^{(23,24)}$. The existence of a carbonyl group was indicated by the UV $\left(\lambda_{\max } 284 \mathrm{~nm}\right.$ ) and ${ }^{13}$ CNMR (at 209.6) spectra. The ${ }^{1}$ HNMR spectrum exhibited signals for two tertiary methyl protons at $\delta 0.79$ and 0.64 , two secondary methyl protons at $\delta 1.15(\mathrm{~d}, \mathrm{~J}=6.9 \mathrm{~Hz})$ and $0.7(\mathrm{~d}, \mathrm{~J}=5.8$ $\mathrm{Hz}$ ) and two anomeric protons at $4.93(\mathrm{~d}, \mathrm{~J}=7.8 \mathrm{~Hz}$ ) and $6.33(\mathrm{br} . \mathrm{s})$. The above data suggested 5 to be a (25R)-spirostanol disaccharide. On acid hydrolysis of 5 (2N hydrochloric acid in dioxane- $\mathrm{H}_{2} \mathrm{O} 1: 1$ ), 5 was hydrolysed to give D-glucose and L-rhamnose as the carbohydrate moieties and an aglycone identified as $3 \beta$ hydroxyl-(25R)-5 $\alpha$-spirostan-6-one (Laxogenin) by its physical and spectral data ${ }^{(28)}$. The structure of the disaccharide was determined by comparison of the carbon assignments with those of reference methyl glycosides ${ }^{(29)}$ indicated the presence of terminal $\alpha$-L-rhamnose unit and an inner $\beta$-D-glucopyranosyl unit joined at C-2. Accordingly, the structure of 5 was formulated as (25R)-3 $\beta-5 \alpha-$ spirostan-6-one-3-O- $\alpha$-L-rhamnopyranosyl-( $1 \rightarrow 2)-\beta$-D-glucopyranoside.

Compound 6 is a major constituent $[\alpha]_{D}^{20}-76(\mathrm{MeOH})$. The post. FABMS showed a molecular ion peak at $\mathrm{m} / \mathrm{z} 885(\mathrm{M}+\mathrm{H})^{+}$, constituent with the molecular formula $\mathrm{C}_{45} \mathrm{H}_{72} \mathrm{O}_{17}$. The ${ }^{1} \mathrm{HNMR}$ spectrum exhibited three secondary methyl proton signals at $\delta 1.77(3 \mathrm{H}, \mathrm{d}, \mathrm{J}=6.2 \mathrm{~Hz}), 1.63(3 \mathrm{H}, \mathrm{d}, \mathrm{J}=6.2 \mathrm{~Hz}), 1.16$ $(3 \mathrm{H}, \mathrm{d}, \mathrm{J}=6.9 \mathrm{~Hz})$, two tertiary methyl proton signals at $\delta 1.06$ and 0.85 and three anomeric proton signals at $\delta 6.38(\mathrm{br}, \mathrm{s}), 5.84(\mathrm{br}, \mathrm{s})$ and $4.94(\mathrm{~d}, \mathrm{~J}=7.4 \mathrm{~Hz})$. The 
signals at $\delta 1.77$ and 1.63 were due to 6-deoxyhexoses. The ${ }^{13} \mathrm{CNMR}$ spectrum showed 45 carbon resonances. The ${ }^{1} \mathrm{H}$ and ${ }^{13} \mathrm{CNMR}$ spectra of 6 indicated that the C-27 was modified as hydroxyl-methyl. Acid hydrolysis of 6 gave Dglucose, L-rhamnose and (25S)-spirost-5-en-3ß, 27-diol (isonarthogenin) ${ }^{(30,31)}$. Thus, the structure of 6 was characterized as isonarthogenein-3-O- $\alpha-\mathrm{L}-\mathrm{rham}-$ nopyranosyl-(1 $\rightarrow 2)-\mathrm{O}$-[ $\alpha$-L-rhamnopyranosyl- $(1 \rightarrow 4)-\beta$-D-glucopyranoside

Compound 7 gave a positive Liebermann-Burchard test and Molisch reactions but did not respond to the Ehrlich reagent. It possessed broad absorption IR bands at 3400 and $1040 \mathrm{~cm}^{-1}$ indicating a glycosidic nature. The positive FABmass spectrum gave quasi molelcular ion peak at $\mathrm{m} / \mathrm{z} 923(\mathrm{M}+\mathrm{Na})^{+}$ and $907(\mathrm{M}+\mathrm{Li})^{+}$suggesting that $\mathrm{MW}$ is 900 . The molecular formula of 7 was estimated as $\mathrm{C}_{45} \mathrm{H}_{72} \mathrm{O}_{18}$ by ${ }^{13} \mathrm{CNMR}$ (Table 1) and FABMS spectrometry. On acid hydrolysis, 7 afforded D-glucose and L-rhamnose as sugar moieties identified by TLC with authentic samples. The ${ }^{1}$ HNMR spectrum of 7 exhibited three anomeric protons of sugar components at $\delta 4.91(\mathrm{~d}, \mathrm{~J}=6 \mathrm{~Hz}), 5.82$ (brs.) and 6.36 (brs.). Its ${ }^{13}$ CNMR spectrum exhibited three anomeric carbon resonances at 102.9, 102 and 100.3. Therefore, one glucosyl and two rhamnosyl units must be contained in saponin 7. Comparison of ${ }^{13} \mathrm{CNMR}$ data of the sugar moieties in 7 with methyl $\beta$-D-glucopyranoside indicated that the $\mathrm{C}-2$ and $\mathrm{C}-4$ of the glucosyl moiety were shifted downfield to 78 and 78 from 74.8 and 70.3 respectively ${ }^{(32)}$. The significant glycosylation shifts clearly showed that two terminal rhamnopyranoses were linked to the C-2 and C-4 positions of the inner glucopyranose $^{(32)}$. The anomeric proton signal of the glucose of 7 at $4.9(\mathrm{~d}, \mathrm{~J}=6.2$ $\mathrm{Hz}$ ) showed that the glucosyl band of 7 had the $\beta$-configuration, however, on the basis of the coupling constant of anomeric proton of rhamnose in the ${ }^{1} \mathrm{HNMR}$ spectrum an $\alpha$ and $\beta$ nature could not be deduced, but $\alpha$-rhamnose could be identified from its ${ }^{13}$ CNMR chemical shift with $\mathrm{C}-5$ of $\alpha$ - and $\beta$-rhamnose appearing at $\delta \quad 69.4$ and 73.5 respectively ${ }^{(32)}$. The $C-5$ signals of two rhamnose units in compound 7 were at 69.4 and 70.3 respectively, thus indicating that the two rhamnose units have the $\alpha$-configuration. 
Also, ${ }^{13}$ CNMR spectrum of 7 exhibited a resonance at $\delta 90$ of a quaternary carbon bearing an oxygen atom. In its ${ }^{1} \mathrm{HNMR}$ spectrum, the appearance of a quartet at $\delta 2.29(\mathrm{~J}=7.2 \mathrm{~Hz})$ due to $\mathrm{H}-20$ methine proton which only coupled to the 21-Me protons, suggested the occurrence of an $\alpha$-hydroxyl groups at $\mathrm{C}-17$ position. In addition, the ${ }^{13} \mathrm{CNMR}$ chemical shifts of the carbons of $\mathrm{A}, \mathrm{B}, \mathrm{C}, \mathrm{D}$ and $E$ rings of 7 were in accord with those of pennogenin glycoside ${ }^{(33)}$ indicating that the aglycone of 7 possessed $17 \alpha$ hydroxyl- $\Delta^{5}$-spirostanol skeleton. The IR spectrum of 7 lacked the characteristic normal F-ring spirostene bands at 980 , 920,900 and $880 \mathrm{~cm}^{-1}{ }^{(23)}$ indicating ring $\mathrm{F}$ substitution. By comparison of the ${ }^{13} \mathrm{CNMR}$ spectrum of 7 with that of pennogenin glycoside ${ }^{(33)}, \mathrm{C}-27$ of 7 shifted downfield to $\delta 64.4$ from 17.2 , thus, a hydroxyl group must be located at C-27 and this was also confirmed by the lack of secondary methyl protons of $\delta<1$ in its ${ }^{1}$ HNMR spectrum. The C-25 configuration of 7 was deduced to be $\mathrm{S}$ from its ${ }^{1} \mathrm{HNMR}$ spectrum. The strong band at $993 \mathrm{~cm}^{-1}$ in the IR spectrum corresponded to that at $995 \mathrm{~cm}^{-1}$ in isonarthogenin ${ }^{(34)}$ suggested the presence of hydroxymethyl on C-25 and revealed its 25 S-spirostanol behaviour. In the ${ }^{1}$ HNMR spectrum, the coupling constant of $\mathrm{H}-25$ in the axial position and hydroxymethyl in the equatorial position ${ }^{(31)}$. In the ${ }^{13} \mathrm{CNMR}$ spectrum of 7 the chemical shift of $\mathrm{C}-3$ at $\delta 78.2$ revealed that the compound was the $3-0$-glycoside ${ }^{(20)}$. Thus 7 is $25(\mathrm{~S})$ spirost-5-en-3 $\beta, \quad 17 \alpha, 27-$ triol-3-O-[ $\alpha$-L-rhamnopyranosyl-(1 $\rightarrow 2)][\alpha-\mathrm{L}-$ rhamnopyranosyl-( $1 \rightarrow 4)$ ]- $\beta$-D-glucopyranoside. 
Table 1. ${ }^{13} \mathrm{CNMR}$ chemical shifts of compounds from $1-7$..

\begin{tabular}{|c|c|c|c|c|c|c|c|}
\hline C & 1 & 2 & 3 & 4 & 5 & 6 & 7 \\
\hline 1 & 37.1 & 37.3 & 37 & 37 & 36.7 & 37.5 & 37.5 \\
\hline 2 & 31.2 & 29.6 & 30 & 30 & 37.4 & 30.2 & 30 \\
\hline 3 & 71.6 & 71.7 & 77.7 & 78 & 77 & 78.2 & 77.8 \\
\hline 4 & 42.1 & 30.8 & 39.2 & 39.1 & 27 & 39 & 39 \\
\hline 5 & 140.7 & 51.8 & 140.8 & 140.8 & 56.4 & 140 & 140 \\
\hline 6 & 121.3 & 69.3 & 121.4 & 121.4 & 209.6 & 122 & 122 \\
\hline 7 & 32 & 41.6 & 31.8 & 31.8 & 46.7 & 32.4 & 32.1 \\
\hline 8 & 31.2 & 33.9 & 30.9 & 31 & 37.4 & 31.7 & 32.4 \\
\hline 9 & 50 & 54 & 52.3 & 52.3 & 53.7 & 50.4 & 50 \\
\hline 10 & 36.5 & 37 & 37.6 & 37.6 & 40.8 & 37.2 & 37 \\
\hline 11 & 21 & 21 & 21.1 & 21 & 21.5 & 21 & 21 \\
\hline 12 & 40 & 40 & 39.9 & 40 & 39.6 & 39 & 32 \\
\hline 13 & 40.5 & 41 & 40.8 & 41 & 41.1 & 40.5 & 44 \\
\hline 14 & 57 & 56 & 56 & 56 & 56.5 & 56 & 53 \\
\hline 15 & 32 & 32 & 31.6 & 31.7 & 31.8 & 32 & 32 \\
\hline 16 & 81 & 80.6 & 81.1 & 81.1 & 80 & 81 & 90 \\
\hline 17 & 62 & 62.2 & 62.9 & 62.9 & 62.8 & 63 & 90 \\
\hline 18 & 16.5 & 16 & 16.4 & 15.9 & 16.5 & 16.4 & 17 \\
\hline 19 & 19.5 & 14 & 19.4 & 18.8 & 13.3 & 19.4 & 19.4 \\
\hline 20 & 42 & 42.1 & 42 & 42.7 & 42 & 42.1 & 45 \\
\hline 21 & 14.6 & 14.3 & 15 & 13.9 & 15 & 15.1 & 9.7 \\
\hline 22 & 110 & 109 & 109.3 & 109.4 & 109.3 & 109 & 110 \\
\hline 23 & 31.5 & 31.5 & 31.8 & 32 & 31.8 & 31.6 & 32 \\
\hline 24 & 29 & 29 & 29.3 & 29.6 & 29.4 & 24 & 24 \\
\hline 25 & 30.3 & 30 & 30.6 & 30.6 & 30.7 & 39 & 39 \\
\hline 26 & 66.8 & 66.8 & 66.9 & 67 & 66.7 & 64.1 & 64 \\
\hline 27 & 17.1 & 16.9 & 17.3 & 173 & 17.2 & 64.5 & 65 \\
\hline $1^{\prime}$ & & & 103.2 & 102.9 & 99.6 & 100.4 & 100.3 \\
\hline $2^{\prime}$ & & & 72.7 & 73.4 & 79.8 & 78.8 & 78 \\
\hline $3^{\prime}$ & & & 75.5 & 75.4 & 78.4 & 76.9 & 77 \\
\hline $4^{\prime}$ & & & 70.4 & 80 & 72 & 78 & 78 \\
\hline $5^{\prime}$ & & & 77 & 76 & 78.2 & 77.9 & 77.6 \\
\hline $6^{\prime}$ & & & 62.6 & 61 & 62.9 & 61.4 & 61 \\
\hline $1^{\prime \prime}$ & & & & 107.1 & 102.2 & 102 & 102 \\
\hline $2^{\prime \prime}$ & & & & 75.2 & 72.6 & 72.5 & 72 \\
\hline $3^{\prime \prime}$ & & & & 78.7 & 72.9 & 72.8 & 72.7 \\
\hline $4^{\prime \prime}$ & & & & 72.3 & 74.2 & 74.2 & 73.9 \\
\hline $5^{\prime \prime}$ & & & & 78.4 & 69.5 & 69.2 & 69 \\
\hline $6^{\prime \prime}$ & & & & 63.2 & 18.7 & 18.7 & 18.6 \\
\hline $1^{\prime \prime \prime}$ & & & & & & 103 & 102.9 \\
\hline $2^{\prime \prime \prime}$ & & & & & & 72.6 & 72 \\
\hline $3^{\prime \prime \prime}$ & & & & & & 72.9 & 72.8 \\
\hline $4^{\prime \prime \prime}$ & & & & & & 74 & 74 \\
\hline $5^{\prime \prime \prime}$ & & & & & & 70 & 70 \\
\hline $6^{\prime \prime \prime}$ & & & & & & 18 & 18.5 \\
\hline
\end{tabular}

Spectra for compounds 1,2 were done in $\mathrm{CDCl}_{3}$

Spectra for compounds 3-7 were done in pyridine $d_{5}$ 
F.A. Abbas:
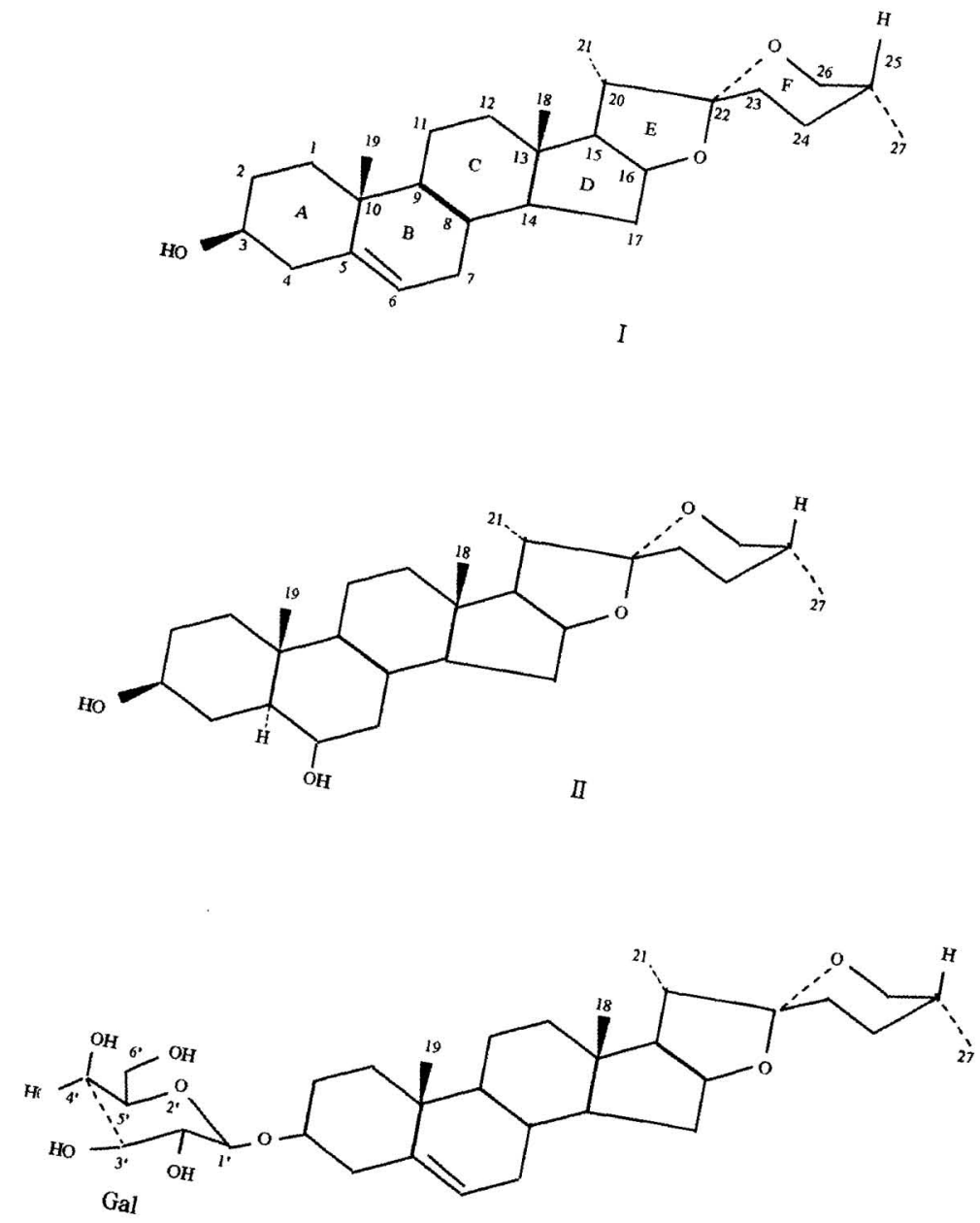

III

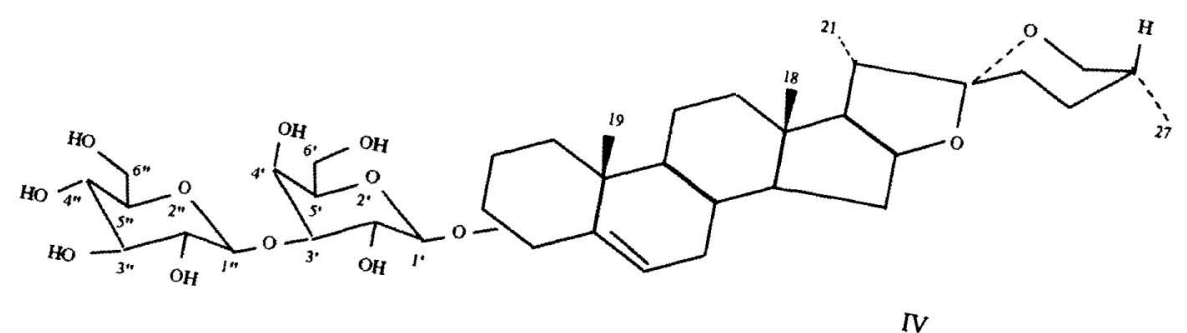




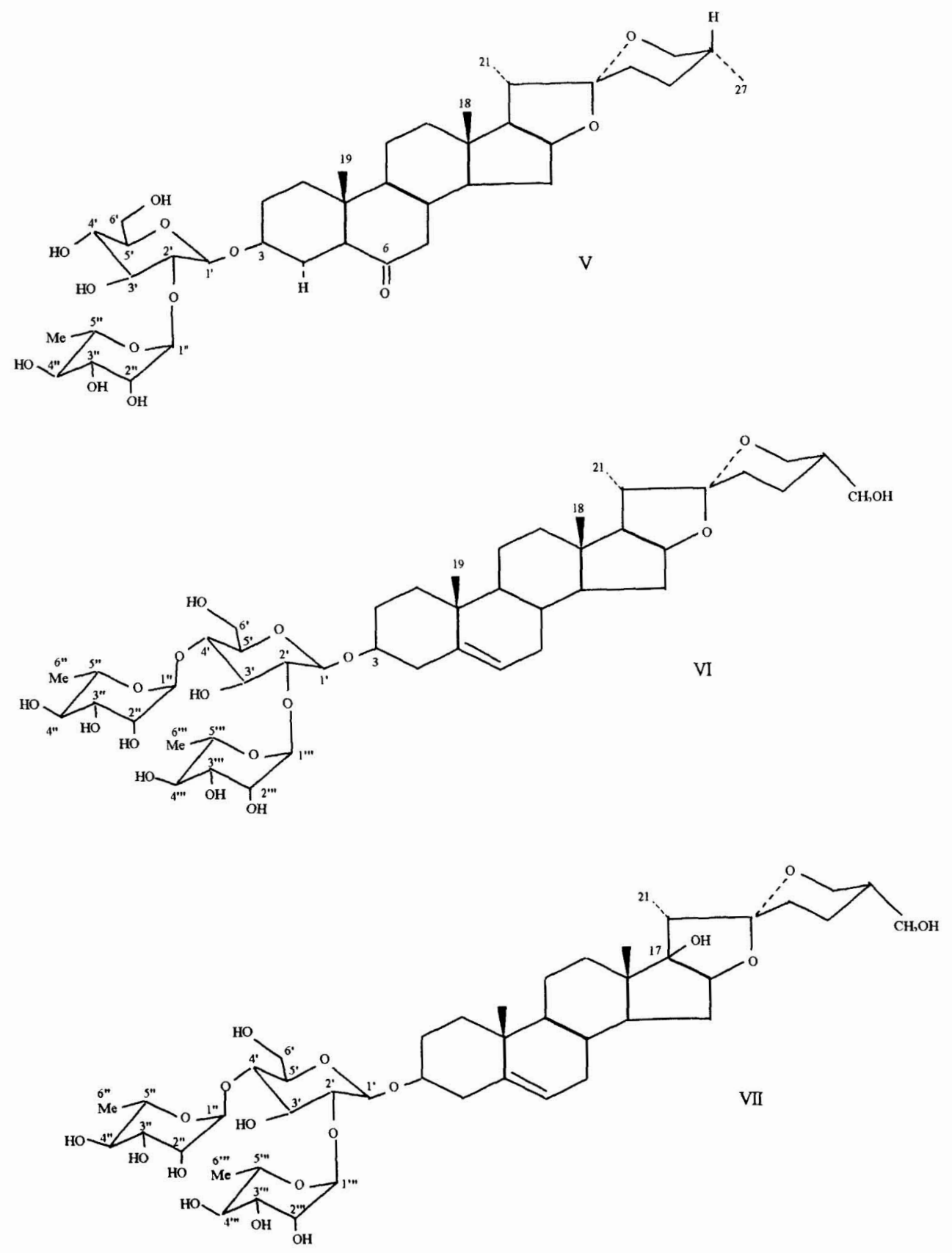




\section{REFERENCES}

1. Ripperger, H., Schreiber, K. and Budzikiewicz, H.; Chem. Ber. 100, 1741 (1967)

2. Ripperger, H. and Schreiber, K; Chem. Ber. 101, 2450 (1968).

3. Noviuzov, E.N., Aslanove, S.M., Ismailov, N.M. and Imanova, A.A.; Khim. Prir Soedin 11, 434 (1975).

4. Coune, C. and Denolel, A.; Plant. Med. Phytoether. 9, 14 (1975).

5. Puri, R.K. and Bhatnagore, J.K.; Phytochemistry 14, 2096 (1975)

6. Zacharius, R.M. and Osman, S.F.; Plant Sci. Letters 10, 283 (1977).

7. Chakravorty, A.K., Dhar, T.K. and Pakrashi, S.C.; Tetrahedron Letters 3875 (1978).

8. Chakravorty, A.K., Saha, C.R. and Pakrashi, S.C.; Phytochemistry 18, 902 (1979).

9. Mahato, S.B., Sahu, N.P., Ganguly, A.N., Kasai, R. and Tanaka, O.; Phytochemistry 19, 2017 (1980).

10. Osman, S., Sinden, S.L., Gregory, P.M., Baker A., and Seiden, K.; Phytochemistry 21, 472-473 (1982).

11. Usubillaga A.N. and Meccia, G.; J. Nat. Prod. 50, 636-641 (1987).

12. De Valeri B. and Usubillaga, A.; Phytochemistry, 28, 2509-2511 (1989).

13. Gan, K.H., Lin, C.N and Won, S.J.; J. Nat. Prod. 56, 15-21 (1993).

14. Ferreira, F., Vazquez, A., Moyna, P. and Kennel, L.; Phytochemistry 36, 1473-8 (1994).

15. Ferreira, F., Soule, S., Vazquez, A., Moyna, P. and Kenne, L.; Phytochemistry 42 (1409-16) 1996.

16. Putalun, W., Xuan, L.J., Tanaka, H. and Shoyama, Y.; J. Nat. Prod. 62, 181-3 (1999) 
17. Sarg, T.M., Glombitza, K.W., Hafez, S.S., Farrag, N.M. and Abbas, F.A.; Pharm. World Sci. 17, 191-4 (1995).

18. Roman, P., Tuck, C.W. solasodine and diosgenin ${ }^{1} \mathrm{H}$ and ${ }^{13} \mathrm{C}$ assignments by two-dimensional NMR spectroscopy. Magn Reson Chem. 32, 278-82 (1993).

19. Eggert, H. and Djerassi, C.; Tetrahedron Lett., 3635 (1975).

20. Tori, K., Seo, S., Terui, Y., Niskikawa, J. and Yasuda, F.; Tetrahedron Lett. 2405 (1981).

21. Stothers, J.B. Carbon- ${ }^{13}$ NMR spectroscopy. New York: Academic Press, 1972.

22. Budzikiewicz, H., Djerassi, C. and Williams, D.H., "Structure Ellucidation of Natural Products by Mass Spectrometry" Vol. 2, Holden Day, San Francisco 110 (1964).

23. Wall, M.E., Roland Eddy C., Mac. Clenann, M.L. and Klumpp, M.E.; Anal. Chem. 24, 1337 (1952).

24. Roland Eddy C., Wall, M.E., and Klumpp Scott M.; Anal. Chem., 25, 266 (1953).

25. Wall, M.E., Krider, M.M., Rothman, E.S. and Roland Eddy, C.; J. Biol. Chem. 198, 533 (1952).

26. Andres,N., Daisy, M., Marruan, S.M.; ${ }^{13}$ CNMR spectroscopy of solasodine glycosides from Solanum laciniatum; Phytochemistry 27, 6035 (1988).

27. Kintya, P.K., Mashchenko, N.E., Kononova, V.I. and Lazurevskii, G.V., Khim.Prir Soedin 267 (1976).

28. Matsuura, H., Ushiroguchi, T., Itakura, Y. and Fuwa, T.; Chem. Pharm Bull 37, 1390 (1989).

29. Agrawal, P.K., Jain, D.C., Gupta, R.K. and Thaker, R.S.; Phytochemistry 24, 2479 (1985). 
30. Minato, H. and Shimaoka, A.; Chem. Pharm. Bull. 11, 876 (1963).

31. Blunden, G. and Patel, A. V.; J. Nat. Prod. 49, 687-689 (1986).

32. Soe, S., Tomita, Y., Tori, K. and Yoshimura, Y.; J. Am. Chem. Soc. 100, 3331 (1978).

33. Chen, C. and Zhou, J, ; Acta Botan. Yunnan, 9, 239 (1987)

34. Takeda, K., Minato, H., Shimaoka, A. and Matsui, Y.; J. Chem. Soc. 4815 (1963). 